\title{
Using Anthropological Principles to Transform the Teaching of Human "Difference" and Genetic Variation in College Classrooms
}

\author{
Amelia R. Hubbard ${ }^{1} \cdot$ Laurel A. Monnig $^{1}$ \\ Accepted: 18 September 2020 / Published online: 15 October 2020 \\ (C) Springer Nature B.V. 2020
}

\begin{abstract}
Exposure to information about genetics is at an all-time high, while a full understanding of the biocultural complexity of human difference is low. This paper demonstrates the value of an "anthropological approach" to enhance genetics education in biology, anthropology, and other related disciplines, when teaching about human differences such as race/ethnicity, sex/gender, and disability. As part of this approach, we challenge educators across social and natural sciences to critically examine and dismantle the tacit cultural assumptions that shape our understanding of genetics and inform the way we perceive (and teach about) human differences. It calls on educators from both social and natural science disciplines to "de-silo" their classrooms and uses examples from our biological anthropology and sociocultural anthropology classrooms, to demonstrate how educators can better contextualize the "genetics" of human difference in their own teaching. Numerous opportunities to transform our teaching exist, and we are doing a disservice to our students by not taking these critical steps.
\end{abstract}

\section{Introduction}

Since the sequencing of the human (and Neanderthal) genome, researchers' understanding of the contributing biological forces that make us "human" has increased exponentially. Complex topics such as epigenetics (see, e.g., Goldberg et al. 2007), proteome-genome interactions (see, e.g., Graves and Haystead 2002), and the functions of "junk DNA" (see, e.g., Palazzo and Gregory 2014) remain at the forefront of recent discoveries, yet the understanding of these concepts and the role they play in shaping human differences remains insufficiently and inaccurately understood by non-geneticists (Barbujani et al. 2013; Kimel et al. 2016; Kolstø 2001; Petty et al. 2000; Schommer-Aikins and Hunter 2002). Three factors potentially contribute to these misconceptions:(1) public exposure to misleading messages about genetic

Amelia R. Hubbard

amelia.hubbard@wright.edu

1 Department of Sociology and Anthropology, Wright State University, 270 Millett Hall, 3640 Col. Glenn Hwy, Dayton, OH 45435, USA 
concepts, (2) the compartmentalization of knowledge within the academy obfuscates the exchange of strategies for tackling such misconceptions among disciplines, and (3) an overall lack of attention to such topics in the classroom.

First, while the public's (our students') exposure to information about genetics is at an alltime high, what they glean about genetics and its role in shaping human social identities is both confusing and incomplete (Bates 2005; Christensen et al. 2010; Condit 2001; Donovan 2014, 2015; Donovan et al. 2019a, b; Gelman and Taylor 2000; Haga et al. 2013; Hubbard 2017a; Kolstø 2001; Lanie et al. 2004; Petty et al. 2000; Smerecnik et al. 2008; Williams and Eberhardt 2008). One way this information is transmitted is through the personalized genetics craze popularized by such companies as 23 andMe. Take for, example, the recent ad campaign by AncestryDNA to "Discover your story," in which individuals share the "unknown" genetic ancestry found in their results. These ads strongly imply that genetic information can unlock the secrets of the individuals' cultural identities so much so that they can use "AncestryDNA results [to] play a unique Spotify mix of music, inspired by your origins" (Ancestry 2018). In several commercials, the discovery of such "biological" identities leads individuals to adopt new cultural or ethnic identities (e.g., when Ancestry user Lyn Johnson puts on a Nigerian Gele). Such claims, therefore, send a strong message that "cultural identity" (e.g., race and ethnicity) is only truly knowable through "biological identity" (i.e., genetic ancestry) and that "biological identity" takes primacy over "cultural identity." Equally damaging is the lack of nuanced explanations for the interplay between one's cultural environment (e.g., socially created structures), physical environment (e.g., ecological variability), and (diverse) physiological (yet relatively restricted) genetic variability in shaping nearly every human phenotype. As a result, the average consumer is left with genetically deterministic beliefs, in which the role of genetics is inaccurately overemphasized and falsely believed to be the all-encompassing and tidy explanation for human identity and behavior (Dar-Nimrod and Heine 2010; Lynch et al. 2018).

Second, the structure of academia has contributed to a siloing of academic scholarship and knowledge within disciplines and sub-specialties (e.g., see Becher and Trowler 2001). Specifically, the pressure on university faculty to "publish or perish" (despite declining grant funding and increased competition) means usually (1) more time is focused on the research missions of institutions over teaching and public outreach and (2) our research is focused on a narrowly defined audience of other academics. The result is a tremendous loss of opportunities to work together (rather than in parallel) to debunk common and pervasive misconceptions about science generally and genetics specifically. Instead, the benchmark for excellence continues to be the dissemination of new scientific ideas within academic disciplinary borders, despite the calls for scientists who can communicate their science to a broader audience inside and outside of the classroom (Brownell et al. 2013; Greenwood and Riordan 2001; Leshner 2003; Stilgoe et al. 2014).

Compartmentalization of our own research also leads to disciplinary-specific views of who should be teaching particular concepts within a particular topic. Classrooms covering the topic of human identities such as sex, gender, race, ethnicity, and even disability usually reflect a dichotomy in which social scientists tend to primarily teach social-cultural issues related to diversity (i.e., stereotypes), whereas natural scientists tend to focus on the biological contributions (or lack thereof) to these human differences. Concomitantly, social science educators contribute by shying away from discussing the "biology" of human differences and defaulting to discussions of race as simply a social construct, despite ongoing evidence that this approach is equally problematic in dismantling genetic essentialism (e.g., Hartigan 2006; Morning 2014; 
Mukhopadhyay et al. 2014; Thompson 2006). If the academic system is not designed to reach across disciplines in designing tools to dismantle misconceptions about genetics and human difference, then social science educators must take on the responsibility of reaching out to natural science educators and vice versa.

Third, at the most fundamental level, both natural and social science educators are doing a disservice in teaching about human difference by skipping the important work of building relevant topics about human biology and culture/society into their courses. Yet, at all levels of education there exists tremendous opportunity to cross some of the artificial borders of "biology" versus "culture" to profoundly shape public understanding of science. At the college level in particular, there is an even greater missed opportunity to contextualize and share information on biocultural concepts of genetics and human difference in general education courses and large-format courses, which often comprise future doctors and health professionals as well as future academics.

As anthropologist Paul Baker (1997) notes, any phenotype is influenced by a mixture of genes (e.g., genetic "potential," innate behaviors), contributions from the physical environment (e.g., natural resources, climate, etc.), and the sociocultural environment (e.g., norms, values, learned behaviors). Baker deems this the "biocultural approach" to human phenotypes. The biocultural approach for teaching about human differences in genetic classrooms is supported by the work of Hubbard (2017a, b) and Donovan et al. (2019a) when talking about race and Donovan et al. (2019b) for gender. Hubbard (2017a) found that a biocultural approach to talking about race and racism in her class led to significant improvement in understanding of four key concepts about the abiological yet socially relevant components of race after one to two exposures to materials presented in Hubbard (2017b). Donovan et al. (2019a) found some reduction in genetic, biobehavioral, and biosomatic essentialism among middle and high school students and adults, through a biocultural framework for teaching about race. Additionally, long-term retention and impact of these ideas were demonstrated. Donovan et al. (2019b), using coverage of gender in textbooks, prepared two treatments: the first comparing human and plant sexual dimorphism and the second examining sexism in science. They found an increase in neurogenetic beliefs (i.e., that gendered differences are brain based and genetically based) for treatment one (traditional explanation of sexual dimorphism and genetics). In treatment two (non-traditional sexism in science approach), there was a significant reduction in neurogenetic essentialism for females (but less so for males). These texts provide some support for the biocultural approach by demonstrating that change to pre-existing beliefs about human difference is possible.

Though the reasons why many faculty are not covering the biocultural aspects of human difference in their classes have not been systematically studied, the implications of a singular, decoupled approach are clear. For example, in studies looking at people's understanding of race, those who were only exposed to the abiological nature of race tended to perceive race as "not real," concluding that the solution to racism was to be "colorblind" (i.e., ignore race altogether) (e.g., Hartigan 2006; Morning 2014). These findings are concerning, given that colorblind approaches have been shown to limit progress in eliminating racism (Apfelbaum et al. 2008; Norton et al. 2006; Plaut et al. 2018) by treating race/racism as unimportant unless biologically real. Further, genetics and human difference cannot be understood without understanding the discriminatory and oppressive ideologies that uphold these identities (i.e., racism, sexism, ableism, etc.) and vice versa. Ignoring the biocultural ramifications of race in the classroom deprives students of the opportunity to learn how racism (a sociocultural phenomenon) affects our physical bodies and even epigenomes (biological outcomes) 
(Gravlee 2009; Morning 2011). Numerous studies demonstrate that overemphasizing the abiological nature of human differences without exploring alternative sociocultural explanations, thereby leaving students to fill in the blanks on their own, is the least effective way to dispel common myths (Donovan 2014, 2015; Lieberman et al. 1992; Morning 2008, 2011; Snyder and Broadway 2004; Thompson 2006). Further, by not intentionally bridging these gaps in information, educators leave novice learners with the impression that they have all the information when in fact they are making deeply ill-informed assumptions, further cementing such ideas long-term (e.g., see Nyhan and Reifler 2015). And this matters immensely, especially when studies are beginning to demonstrate how intentionally introducing such topics into the classroom can reduce racial bias (e.g., Donovan et al. 2019a) and gender bias (e.g., Donovan et al. 2019b).

\section{A Call to Transform the Way We Teach Human Genetics}

In light of these three issues, we call on both social and natural scientists to work together to introduce a more nuanced approach to teaching about human difference and the role of human genetics. For the purpose of this special issue, however, we focus more on topics within the natural sciences that can enhance specific genetics content. In this effort, we demonstrate how deploying some of the fundamental principles of a four-field anthropological approach can transform the way we prepare to teach such complicated topics. In this paper, we use our own introductory biological anthropology (natural science credit) and cultural anthropology (social science credit) classrooms as an example of success in addressing the three contributing factors described above.

While the contexts of our classrooms differ in terms of specific content, both share the goal of understanding humans bioculturally (not as products of either nature or nurture). The transformation of our courses into the spaces we will describe in this paper came about through ongoing conversations and years of trial and error. Our content has not changed significantly, but our approaches to teaching this content have been altered radically, as we have discovered what explicit versus tacit assumptions we bring to these spaces. Here, we use anthropological concepts and ways of thinking that ask educators to question their own tacit assumptions about science, genetics, and human biocultural differences. As such, the ultimate purpose of this paper is to demonstrate the context that anthropology can provide as an epistemological framework on which to base the design of one's own course topics on human difference and genetics.

\section{What is an "Anthropological Approach"?}

As Wolf (1964) notes, Alfred Kroeber is often quoted as saying that "Anthropology is the most humanistic of the sciences and the most scientific of the humanities" (88). No other discipline covers the depth of time (archeology), cross-cultural variation (sociocultural anthropology), impacts of language (linguistic anthropology), and bioculturally rich record (biological anthropology) of human difference. Collectively these four subfields are rooted in holism, cultural relativism, cross-cultural inquiry, and biocultural frameworks for studying humans and related primates through time and across space (see Table 1). In the classroom, an anthropological approach would involve the application of one or more of these concepts 
Table 1 An overview of the four core elements of an anthropological approach

\begin{tabular}{|c|c|c|}
\hline Concept & Definition & Connection to genetics \\
\hline Holism & $\begin{array}{l}\text { The notion that humans are shaped by a variety } \\
\text { of factors (across geographic space and } \\
\text { time)-social/cultural, linguistic, biological, } \\
\text { psychological, and environmental and } \\
\text { scientific analysis of humanity cannot be } \\
\text { reduced to a single feature or the sum of } \\
\text { each contributing factor (e.g., see Borofsky } \\
\text { 1994; Malinowski 1922; McGee and } \\
\text { Warms 1996). }\end{array}$ & $\begin{array}{l}\text { Sociocultural knowledge, language, } \\
\text { environmental variation, and biological } \\
\text { factors all contribute to human differences } \\
\text { (e.g., American perceptions of behavioral } \\
\text { differences based on race are shaped by the } \\
\text { language used to describe these behaviors, } \\
\text { socially specific classifications of racial } \\
\text { differences, and the meaning we ascribe to } \\
\text { biologically based characteristics like skin } \\
\text { color) }\end{array}$ \\
\hline $\begin{array}{r}\text { Biocultural } \\
\text { approach }\end{array}$ & $\begin{array}{l}\text { An approach that recognizes human variation } \\
\text { (in the broadest sense) is best understood as } \\
\text { the interplay between genotypes, cultural } \\
\text { environments, and physical environments } \\
\text { (e.g., see Baker 1997; Wiley and Allen } \\
\text { 2017) }\end{array}$ & $\begin{array}{l}\text { Humans are not the product of either nature or } \\
\text { nurture, but a complex, nuanced mix of both } \\
\text { (e.g., differences in human sexual desire are } \\
\text { influenced by dopamine receptors and the } \\
\text { genes that control them (biology), cultural } \\
\text { norms of expression, and even the impact of } \\
\text { temperature changes and time of day on } \\
\text { hormone levels). }\end{array}$ \\
\hline $\begin{array}{l}\text { Cultural } \\
\text { relativism }\end{array}$ & $\begin{array}{l}\text { A theoretical and methodological approach } \\
\text { that asks users to recognize, and where } \\
\text { possible "put aside," the influence of one's } \\
\text { own cultural norms and values when trying } \\
\text { to understand other cultures (e.g., see Harris } \\
\text { 1976; Perry 2003; Marcus and Fischer } \\
\text { 1986). }\end{array}$ & $\begin{array}{l}\text { Americans assume our norms, behaviors, and } \\
\text { assumptions about biology and culture are } \\
\text { shared globally (e.g., there is an assumption } \\
\text { that monogamy (one partner at a time) is } \\
\text { globally more common than polygamy } \\
\text { (multiple partners at a time) monogamy is } \\
\text { actually less common) }\end{array}$ \\
\hline $\begin{array}{l}\text { Cross-cultural } \\
\text { inquiry }\end{array}$ & $\begin{array}{l}\text { An approach that uses and values information } \\
\text { (qualitative and quantitative) from cultures } \\
\text { other than one's own. In addition, only } \\
\text { through examining the global span of } \\
\text { human cultural diversity can we understand } \\
\text { what is and what is not human (e.g., see } \\
\text { Goodenough 1970; McGee and Warms } \\
\text { 1996). }\end{array}$ & $\begin{array}{l}\text { Much of what Americans think they know } \\
\text { about human difference is socially and } \\
\text { culturally specific (e.g., the contemporary } \\
\text { American notion that "gender" is a recent } \\
\text { construct versus "two spirit" identities } \\
\text { among certain indigenous American } \\
\text { communities) }\end{array}$ \\
\hline
\end{tabular}

(ideally all, when possible), to contextualize the very nature of what we think we know about human difference.

These four guiding principles of anthropology should not remain siloed, as they are valuable in thinking about a more robust genetics curriculum. Furthermore, the events of 2020 have dramatically spotlighted the necessity of an anthropologically informed framework. Front and center are the wider societal contexts in which ideas about biology and genetics (COVID pandemic) and race (recent protests for racial justice) and the intersections of the two (e.g., race-based disease susceptibility, US anti-Chinese sentiments about the "release" of these diseases). This year, COVID-19 led to an international "shutdown" as researchers and educators rushed to learn more about the origins and spread on this disease. Much of the media coverage between January and May initially focused on the behavior of novel coronaviruses such as mutation rates, the structure of the virus itself, and for how long the virus could last on surfaces and in the air. As social scientists, we noticed the palpable absence of human behavior and culture in these discussions. For example, in coverage of mask wearing the primary focus seemed to be on the size of the filter needed to restrict viruses passing through a homemade mask. Many social media posts concluded that wearing a mask was 
socially responsible. Yet, in our own experiences, there were undiscussed and critical components - class divisions in who had access to masks, differing public opinions about the efficacy of masks, differential treatment of mask wearers by race, and even behaviors centered around the proper wearing of a mask. By May, the discussions finally began to shift from purely COVID-based concerns to glaring racial inequities spurred by the killing of several black Americans by police and culminating in global protests over the murder of George Floyd. Almost as soon as this shift occurred, more emphasis began to be placed on educators and the general public wondering why does COVID affect black, indigenous, and people of color (BIPOC) more severely. Moving into the year ahead, many educators also started asking "How do we incorporate an 'anti-racist' biology into our classrooms?'.

Given the changing societal landscape described above, intellectual and academic siloing of varied perspectives cannot continue. A more effective nuanced approach to biological education is an indispensable component to combating persistent biological essentialisms that prevent progress in racial and social inequality. Specifically relevant for this paper, classrooms covering genetic topics can immediately benefit from the incorporation of the proposed concepts into their coursework. Developing a framework of cultural relativism primes the classroom to have a less judgmental conversation about misconceptions and behaviors that seem "foreign" to us but "normal" to others. Examples of cross-cultural experiences of the disease (e.g., norms surrounding mask wearing in Japan and China versus the US in reducing spread, or Senegal's rapid development of cheap, reliable at-home genetic testing for rural communities) can further prompt shifts in thinking holistically about the disease. Holism is the perspective that allows us to discuss the ramifications of racism as a system of oppression that creates both limited access to needed resources and chronic stress responses in the body (a biocultural phenomenon)—something sorely lacking in most pre-med curriculum.

Anthropology is not the sole antidote for dispelling myths or improving teaching practices. As with other disciplines focusing on humans, anthropology has been marked by a complex history of promoting race-based science (e.g., see Hutchings and La Salle 2015; Ifekwunigwe et al. 2017; Marks 2017; Mullings 2005; Wagner et al. 2016), sexism (e.g., see Clancy et al. 2014; Fuentes 2012; Hrdy 1981) and ableism (e.g., Doat 2014; Friedner et al. 2018). Instead, we contend that the fundamental principles of anthropology can be applied in a way that not only contextualizes these concepts but also aids students in developing a more nuanced understanding of human genetics overall. The work of pioneers such as Franz Boas, Margaret Mead, Ruth Benedict, and Zora NealeHurston remains highly relevant in dismantling racist and gendered pseudo-science, by fundamentally challenging the notion that human differences are biologically encoded, without the influence of cultural beliefs and norms (for a recent review, see King 2019). Recent contributions by anthropologists have also shifted classroom dialogs and public perceptions of race through traveling exhibits (e.g., Mukhopadhyay et al. 2014) and cooperative research (e.g., Bardill et al. 2018), studies of sexism in the field and our workplaces (e.g., Clancy et al. 2014), and blogs that call out persistent ableist problems in our discipline (e.g., Friedner et al. 2018). Anthropology, like most disciplines, is trying to do better (e.g., see Antón et al. 2018) and holds tremendous promise for developing perspectives necessary for a complete human genetics curriculum. 


\section{Step One: Exploring our Own Assumptions}

Preparing to add an "anthropological perspective" in the genetics classroom is as much about exploring the tacit sociocultural assumptions we as educators and researchers hold, as it is about changes in specific content and examples. Therefore, this section sets the stage for thinking holistically about the design of class content, by starting with an exploration of ourselves. Part 1 begins with a review of how both educators and students, alike, construct ways of understanding their worlds day-to-day. Here, we ask educators to consider how we think we "know what we know" about human difference, before asking our students to do the same. Such an approach has been supported by research in social psychology and teacher education (e.g., see Cochran-Smith 2005; DiSessa 1993; Gay and Kirkland 2003; Philip 2011). As such, Part 1 is designed to help educators think about the tacit assumptions they bring into their teaching approaches. Part 2, then, addresses specific (and relatively common) misconceptions and biases about genetics and the nature of science, which should be directly addressed in the classroom. Together, the intent is to challenge educators to think about the information, assumptions, and culturally specific skills we and our students bring to the classroom.

\subsection{Part 1: Exploring How We Know What We "Know" About Science}

Before educators can tackle the varied components contributing to human "difference," they must first consider how humans acquire knowledge and cement meaning about such knowledge. Here we focus on three core ideas: (1) humans as categorizers, (2) humans as products of their cultures and societies, and (3) how humans acquire individual identities through lived experience. These ideas mirror principles of the American Anthropological Association's (AAA) project "Race: Are We So Different?" (Goodman et al. 2012), though these core ideas can also be applied to teaching about sex/gender and disability. This section asks you to consider how your own systems of knowledge are affected by your social and cultural ideas about (and training in) science.

\subsubsection{The Need to Classify is Innately Human, but How We Classify is Always Culturally Specific}

From anthropology (e.g., Berlin 1992) to social psychology (e.g., Smith and Medin 1981), there is abundant evidence that humans use classification schema to make sense of the world. Humans cognitively package information about the world into smaller, culturally palatable bits, whether natural, material, or social-cultural. These classifications or categories tacitly force those within that culture to concentrate on some details about a certain phenomenon while ignoring or glossing over other details. Indeed, these classification systems shape a culture's sense of reality. For example, all cultures divide up things that could be eaten in any given environment into the categories of "edible" and "inedible." A glance at any given culture's categories will show that there are many things that can be safely eaten by humans (e.g., crickets) but that people in a particular culture do not find palatable (e.g., Oaxacans find roasted chapulines (grasshoppers) delicious, while many Americans find them, at best, a novelty food item or, at worst, disgusting).

Such categorization is often considered the purview and hallmark of western scientific analysis, as scientists look for patterns and organize data quantitatively and qualitatively into 
describable packages of information. Indeed systematic, "objective" categorization is often thought to be synonymous with "science." However, cross-cultural data demonstrates that, in reality, both non-scientists (Knobe 2010) and non-western peoples (e.g., Smith 2012; Sillitoe 2007; Barnhardt 2005) have equally complex and systematic forms of categorization (science). For example, indigenous Micronesian communities have long used science, akin to "remote sensing," to detect land while navigating at sea (Genz 2018; Genz et al. 2009), while indigenous communities around the world have varied ways of classifying colors (Berlin and Kay 1969). Whether types of sand or physiological differences between people, all humans find it challenging to navigate systems where the variation is high and unordered. Our brains automatically package information into culturally specific categories about the world to more effectively process what could be an overwhelming amount of information and to better navigate the "gray" areas (Mahon and Caramazza 2009; Smith and Medin 1981). The important element of the previous sentence is "culturally-specific categories," because crosscultural data also reveals that the way a group of humans categorizes phenomenon is through a particular cultural lens.

To clarify, anthropologists do not advocate practices that ask people to avoid categorization. Rather, by using frameworks like cultural relativism, we can begin to appreciate that such practices are culturally specific and highly variable. Without doing so, we might tacitly accept the ethnocentric assumption that, because categorization is "universal," the categories we use are objectively "knowable" through science and accepted across all cultures. This assumption is what must be challenged in our own minds and classrooms.

\subsubsection{Humans Do Not Just Evolve Biologically, They Are Also Products of Their Social and Cultural Evolution}

In a seminal anthropological article, Paul Baker (1997) explained that human differences are best understood "bioculturally" as a complex combination of genetic potential, physical environmental variables, and cultural practices. While there is great debate over the uniqueness of human culture as opposed to other animal behaviors, there is strong evidence that humans (as a relatively genetically homogenous species) rely deeply on cultural knowledge and behaviors to adapt to their surroundings. No other primate in our lineage has had to rely as heavily on modification of physical and cultural environments to survive as humans have, in their relatively short time on Earth (e.g., see Potts 2013). This cultural (i.e., generationally passed rather than genetically imbued) information makes human survival possible because of the benefits mentioned above and the ability to pass these complex meaning systems (cultures) to subsequent generations (e.g., see Henrich 2008). Thus the next generation is spared having to, for example, figure out what foods are poisonous or not, how to build appropriate shelters for that particular environment, or even establish normative rules for how people "should" behave within the social group. Each generation tweaks, adds to, interprets, and partially changes the existing pool of cultural knowledge that shapes all things social without having to begin anew. In sum, "cultures" are adaptive systems that constitute the sources of information for how people think and behave.

A significant component of cultural adaptation is myth. The word "myth" has two connotations, much like the word "theory" in science (versus the public's use). In a colloquial sense, myths are false statements. Basic myths about health (e.g., handwashing and bacterial evolution) and the nature of science (e.g., all questions can be tested scientifically) are commonly the focus of biology and classroom discussions. Borrowing from cultural 
anthropologist Clifford Geertz, biological anthropologist Agustín Fuentes (2012) explains that myths are also a cultural form of "common sense" in that they are the (often subconscious) stories we tell ourselves to navigate the people and ideas we encounter. In other words, myths in this sense are narrative "cognitive tools" that help us make sense of things that are not easily explained or things that have seemingly logical contradictions (Lavenda and Schultz 2017). In both contexts, myths are subjective ideas about how things work that can become deeply imbedded components of our cultural fabric. In the context of human differences, such myths can be productive in helping us to make sense of the variation we see and experience in other people and cultures. Yet, such myths can also be very "dangerous" when we assume others hold the same worldviews, allowing us to remain uncritical of why and how we think we know what we "know." Asking ourselves and our students to consider how these sociocultural experiences influence our understanding of genetics can be key to opening up discussions about assumption and bias in genetics research.

\subsubsection{In Individuals, Human Social and Cultural Evolution is Mediated by Lived Experiences}

Both ourselves and our students can benefit from being mindful that our own myths/ worldviews are shaped by lived experience within specific cultural contexts. This distinction serves to nuance the message of enculturation from the point made above: while humans are products of the cultures in which they live, no single individual is ever representative of the group as a whole. Yet, one's unique, lived experience is constrained and shaped by the amount of direct exposure (and access) to varied social-cultural knowledge that circulates within any society. Any individual identity, then, is potentially incongruous with the complex, fluctuating, and sometimes divergent shared pools of cultural knowledge. Unsurprisingly, studies demonstrate the amount and quality of exposure to different ideas shapes our ability to navigate such experiences and critically analyze our own worldviews and categorization systems (e.g., Kuklinski et al. 2000; Nyhan and Reifler 2010, 2015; Schommer-Aikins and Hunter 2002). In other words, those who are exposed to a greater variety of ways of thinking about a particular topic are more open to different types of knowledge and ways of knowing.

Though terminology differs, social and cognitive psychologists also utilize similar concepts to evaluate how humans navigate lived experience. Knobe (2010) evaluated different cognitive pathways in which humans are perceived to apply their lived experience, noting that research has tended to emphasize humans as utilizing only one pathway. In the "person as scientist" model, individuals systematically and objectively evaluate information, while in the "person as moralist" model, information is contextually situated in values and morals to judge validity of knowledge. Knobe concludes that humans utilize a number of frameworks that are contextually specific to decide how much of each framework to follow. In the classroom, acknowledging the power of our own lived experiences allows educators and their students to be more aware of individual variation within groups. This acknowledgment serves as a personal check on assuming everyone thinks about human difference in the same way, as well as an important reminder that individuals within a larger group (biological or social) vary widely.

\subsection{Part 2: Investigating Our Own Myths About Human Differences}

In the previous section, we reviewed some of the ways in which humans make sense of the world through categorization, acculturation, and lived experience. Building on these ideas, we 
posit that a core issue in teaching about human differences in American classrooms is an overreliance and overemphasis on biological explanations. Biology is viewed as an "easier" framework than culture, which is often seen as less objective and "open to interpretation." Yet, there is great irony in the fact that people who rely on biological frameworks have been acculturated to such ideas, so that many of their notions about biology are culturally specific.

Until courses in human biology and genetics include cultural contributions and assumptions about our ways of "knowing," students and the general public will continue to stumble through ideas about human difference from an ideologically biological core. As noted earlier, the tendency for individual disciplines to teach individual pieces of the larger framework (i.e., siloing) is a contributing factor to this segmented coverage. The result is that Americans (and "westerners" more generally) operate on four pervasive sociocultural myths about biology that frame their understanding of the genetics of human difference:

\subsubsection{Myth 1: Biological/Genetic Frameworks for Understanding Human Difference Are More Relevant than Cultural Frameworks}

In studying human difference, it is imperative educators and students begin to acknowledge explicitly that assumptions about biology are informed not only by scientific studies and statistics but also by the meanings prescribed by one's cultural framework and vice versa. Furthermore, our training in "culture" is mediated by what we experience and ultimately can "see." All primates are a highly visually oriented species; therefore, it is unsurprising that vast amounts of literature document how students take contextual clues from and process what we can visibly perceive (see e.g., Barnes-Karol and Broner 2010; Harper 2002). Whether race, gender, sexuality, or disability, humans use visual cues about the physical characteristics of others in this process of categorization, with secondary information coming from behaviors, manner of dress, (body) language use, and other cultural cues. In the context of human difference, however, we privilege and tend to more highly trust what we think we "know" about biology over our cultural intuition.

Take, for example, sex and gender. In the classroom, educators treat these terms as separated by biologically "knowable" differences (sex) and culturally variable personal/ group interpretations of identity (gender). Sex in this "traditional" context is predicated on biology-hormones, (internal) reproductive organs, (external) genitalia, chromosomes, and other physical characteristics (e.g., breasts, facial gracility). Gender, therefore, is seen as the cultural expression of sex. Yet, ask any person to describe how they know someone's sex and they will usually focus on what is visible, such as the shape of the person's body and facial features, as well as their mannerisms, haircuts, and clothing. Without realizing it, people are relying on culturally determined visual markers of "sex" (e.g., standards for a "typical male brow ridge" varies globally). Further, if features like breasts are not readily visible or facial features are perceived to be "in between," a person will usually impose a sex determination based on other cultural markers such as clothing, speech patterns (e.g., deepness of voice), and body language (e.g., how the person sits), to name just a few. Without realizing it, we are using cultural ideas about biology and its connections to behavior to categorize; in essence, our ideas of biology are cultural. Even the ways in which we categorize sexes are deeply flawed given that new research demonstrates at least nine combinations of the traits described above have been identified (e.g., see Ainsworth 2015). Perhaps, like gender, sex should also be considered a spectrum of variation. 


\subsubsection{Myth 2: Most Human Identities Have a Strong or Solely Biological/Genetic Basis; Therefore, by Extension, Human Behavioral Differences Are Genetically (More Than Socially) Encoded}

Biology and culture are strange bedfellows in that theoretical approaches to their relationships vary widely. Franz Boas $(1938,1940)$, the founder of American anthropology, was instrumental in creating a theoretical anthropological approach that challenged popular notions about human behaviors as innate. However, over the years, the "nature versus nurture" debate has raged between more biologically deterministic theoretical camps and more culturally deterministic theoretical camps (Welsch and Endicott 2006; Jackson and Depew 2017). By the 1960s, the "birth" of anthropological genetics brought with it a host of questions about the potential for genetic and cultural co-evolution, a topic of much debate in contemporary genetics (Marks 2012). At its core were debates about the roles of human nature, human nurture, or human nature in combination with human nurture. As Fuentes (2012) notes, some of the most pervasive myths about differences in gender and race have been predicated on notions of an inherent human nature in which, for example, men are born more aggressive (and continue that aggression as biologically timed testosterone activates during growth and development), women are born with an evolutionary imperative to protect their children and insure their DNA's survival through monogamy, and racial differences in disease are due to biological differences. In short, by spotlighting biology in narratives where non-biological factors also play a significant role incorrectly naturalizes human differences (e.g., see Goodman et al. 2012; Hartigan 2006; Sussman 2014; Yudell et al. 2016).

The consequences of a biology-only curriculum are often genetically deterministic frameworks that lead to fatalistic conclusions in which those with particular genes are "doomed" to act out particular behaviors. Dar-Nimrod and Heine (2010) proposed the Genetic Essentialism Framework to explain how people center ideas around behaviors as (1) natural, (2) immutable, and determined, (3) with a specific (biological) etiology leading groups of people to be homogenous and discrete. Using studies from a variety of sources, they demonstrate the more an individual views a behavior as genetically "immutable and determined," the greater the chance they also perceive social groups as immutably determined by one's genes rather than social-cultural phenomena. Lynch et al. (2018) review literature on "causal reasoning" in genetic determinism noting that there exist conflicting results about the perceived origins and causes of "positive" and "negative" physical attributes and behaviors (e.g., are they internally/ genetically derived versus externally/environmentally derived). In particular, Lynch and colleagues note that the magnitude of the perceived desirability of a trait (e.g., helpful vs. harmful) can shift perspectives about their causes (e.g., genetic vs. cultural). As noted earlier, preliminary research suggests that at least some of these essentialist ideas about race (Donovan et al. 2019a; Hubbard 2017a) and gender (Donovan et al. 2019b) can be reduced using our proposed approach.

\subsubsection{Myth 3: Humans Share More Biological "Differences" Than "Similarities"}

While human differences can be expressed as a spectrum of variation, a common scientific categorization process is to establish a baseline of "normal" from which everything that deviates from "normal" is deemed "abnormal". Using statistical frameworks, we attempt to make such categories scientifically objective by introducing concepts like central tendencies and averages, which follow a normal distribution. In the classroom or in science 
communication, the emphasis on representing human variation as finite averages may also indirectly reinforce the importance of "differences," because the vast overlap in variation is hidden. Therefore, models of preparing students to think about human differences should also explore the range of variation that displays the many "similarities."

Take, for example, sexual dimorphism in height. When asked to evaluate whether humans are sexually dimorphic in height, the vast majority of people will note that males are taller on average than females. While such assertions have been tested and cannot be disproven, what happens when individuals are introduced to graphs illustrating distributions of height by sex? In the first author's course, a lab on anthropometrics (living human body measurements) is used to illustrate this point. Students begin by predicting whether height will be sexually dimorphic and then measure and record data on each individual's sex (students select male or female) and height (in centimeters) in an Excel spreadsheet on the projected classroom screen. Averages are calculated for the students and displayed as well. When initially asked if males and females are sexually dimorphic by height (despite only a few centimeters average difference), most conclude that males are taller than females and therefore sexual dimorphism is present. Next, students are asked to find the smallest and tallest person within each sex to formulate a range of height variation and estimate the range of overlap in heights. While some argue short men and tall women outliers skew results, most observe that there is more overlap than non-overlap and, therefore, height is not sexually dimorphic in this context. Following up in class, a graph of the overlap nationally can also be effective in highlighting the many similarities and few differences.

From an anthropological viewpoint, there is also the problem that the samples on which most research is based are not cross-cultural. As Henrich et al. (2010) noted, Americans (and most of the other countries with the majority of research publications) often utilize student or local populations for studies. Therefore, a large proportion of the research subjects in our studies are a small subset of the larger global population and fail to capture the full range of both biological and cultural variation present today. Acknowledging that our data are skewed allows us to consider that, for example, studies of "black" diseases focus disproportionately on Americans, not African or other diasporic communities. It also signals to our students that bodies of scientific knowledge have areas for new development, thereby encouraging them to understand that there is still a lot they need to "know" and explore.

\subsubsection{Myth 4: (Western) Science Is Objective and (Therefore, Universally) Socially/ Culturally Neutral}

Because science relies on the notion of "objectivity," there can exist a false sense that science and science classrooms are "neutral" in their approaches to the study of human differences. Yet, the physical spaces in which people learn, the method of content delivery, and the curricular materials used are all imbued with cultural meaning and context. Anyone who has taught about race, gender, or disability explicitly in their biology courses has likely received a comment that the topic was "political"; our students and the public see through this objectivity. Still, more educators are beginning to acknowledge the importance of culturally relevant curriculum design as a better way to engage students in topics like general biology and genetics (e.g., see Tapia et al. 2018). Work by Bang and Medin (2010) and Bang et al. (2018) demonstrates an example of collaborative community-based research that engages indigenous communities in development of projects and curricular programming. This longterm project acknowledges the value of multiple perspectives in solving environmental 
questions, given that indigenous science values "relationships, reciprocity, and responsibility" (2018). Further, their work with indigenous students has helped to develop culturally relevant curriculum to promote participation in STEM education, while acknowledging the complex and deep history of formal, government education as a means for acculturation in these communities (2010).

Within anthropology and human genetics, progress is also being made in including indigenous perspectives. Projects such as the Summer Internship for the Indigenous Peoples in Genomics (SING) have produced research projects involving scholars from indigenous communities that themselves engage indigenous communities (e.g., Bardill et al. 2018; Claw et al. 2018; Garrison et al. 2019), as well as curriculum that addresses the problematic histories of human genomics (e.g., Garrison 2013) and medical research (e.g., Hodge 2012) in the past and today (e.g., Claw et al. 2017). Projects like these understand and immerse themselves in the fact that science is neither value neutral nor culturally devoid. Unfortunately, many anthropologists have done a generally poor job of extending such information outside of the discipline. Additionally, social scientists need to take up the responsibility of conveying basic messaging about genetics and human difference in our classrooms (Morning 2014). Avoiding these topics leaves students to fill in the blanks, often erroneously (Donovan 2014, 2015; Lieberman et al. 1992; Morning 2008, 2011; Snyder and Broadway 2004; Thompson 2006).

\section{Step 2: Deconstructing Pervasive Myths}

Once educators have completed the first step of exploring our own tacit cultural assumptions about science and human genetics, the next task is to build interventions that deconstruct pervasive, common myths about human differences in genetics courses. As others have noted (e.g., see DiSessa 1993; Hammer 1996), students (like faculty) approach each classroom with their own preconceived notions of science and genetics. This is especially true when addressing complex concepts like race, gender, and disability. One might (and should) incorporate aspects of Step 1 into their presentation of the genetics of human identity. Interweaving concepts such as the nature of scientific inquiry and the limitations of scientific knowledge and practice, within the four principles of anthropology, can provide powerful, memorable context to the specific details of genetic courses. Likewise, interspersing these topics throughout the term via methods such as concept retrieval, question spacing, and interleaving has been demonstrated to improve long-term knowledge retention (see Agarwal and Bain 2019).

This section offers a view into some of the ways the authors teach about gender, race, and disability in their classrooms. This section is not meant to serve as a comprehensive intervention or "how to" manual, given that genetic courses focus on varying combinations of topics within genetics. Likewise, there is no "one size fits all [classrooms]" approach to teaching about human difference in these contexts. Instead, faculty teaching genetic courses will need to do the work to prepare by (1) assessing the impacts of their own identities and the demographic, temporal, and regional impacts of these topics on their students and (2) developing course-specific assessments to see what works for their students. For example, in our Midwestern classrooms, there is a sub-culture of "polite" conversation, requiring an explicit acknowledgment that students may be acculturated to "not talk about race/gender/disability." Hubbard (2017b) presents one example of how to prepare to teach in different classroom contexts, as well as specific questions she used in her classroom to assess student understanding of the biological race myth. 


\subsection{Misconception 1: Race and Ethnicity or Sex and Gender Are Interchangeable Concepts}

Setting up terminology and clarifying distinctions limits confusion for students who are often exposed to these terms as "interchangeable." Yet, few biology/genetics textbooks or courses systematically cover these topics or clarify the important distinctions in these terms (Donovan 2014, 2015; Lieberman et al. 1992; Morning 2008; Willinsky 2020). In the natural sciences, most students learn about sex as a biologically discernible feature based on chromosomal, hormonal, physiological, and potentially neurological differences. Gender may not be a focus or used interchangeably with sex. Most students, if it is not explicitly discussed, will associate "gender" (e.g., masculine, feminine, transgender) as a synonym for "sex" (e.g., male, female, intersex), given that many forms (e.g., medical forms), research articles, and science news pieces use "gender" in lieu of sex as a more "politically correct" alternative. The same issues apply to the use of race/ethnicity, though both are socioculturally defined terms. In the social sciences, definitions are more common though emphasis on the construction of biological ideas about race is covered to varying degrees. As Morning $(2011,2014)$ notes, biological notions of race are creeping into social discourse and both educators and students need to do the work to learn (and be able to explain) why biological/genetic notions of race are inaccurate.

There are alternatives in skipping this terminology and, instead, incorporating the importance of these distinctions into our coursework. For example, Hubbard (2017b) offers a visual and biocultural approach for clarifying what is (and is not) meant by race, ethnicity, and (genetic) ancestry, while Donovan et al. (2019b) offer practical approaches in addressing gendered stereotypes. In our courses, students are introduced to terminology and, throughout the term, are challenged to think about how sex, though a biologically definable term, has a relevant social and gendered context. For example, students are asked to provide an example highlighting how the way we perceive someone's sex (e.g., male) influences how we perceive their gender (e.g., masculine) or gender identity (e.g., man). Students' answers can include what physically observable features, behaviors, or even clothing are used to make this assessment. This conceptual exercise can then expand to larger discussions about assumptions of innate, sexually dimorphic (e.g., neurologically innate differences) and racial differences (e.g., differences in athletic ability) in behavior, and the ramifications of these assumptions (e.g., racism becoming embodied epigenetically). Cross-cultural discussions of the idea of race are particularly helpful in demonstrating how ideas about race and ethnicity, including definitions, are not globally universal. For example, in East Africa and the Pacific, where we conduct our research, ideas about race are deeply tied to (recent) colonial efforts to establish "definable" identities (e.g., see Monnig 2007, 2008) in which racialized phenotypic cues have very different meanings attached to them. In our own courses, noting this difference allows students to further grasp the notion that racial identities are not easily definable across all human groups and therefore ill-suited to compare with genetic identity. To explain the ramifications of mixing terms, there are numerous examples of why conflating gender with sex, for example, has impacts on outcomes in medicine (e.g., see Conger 2017 talking about work Schiebinger and Stefanick 2016).

\subsection{Misconception 2: Because Phenotypic Variation in Humans Is High, So Is Genetic Variation}

"Looks can be deceiving" particularly when there exists an underlying assumption that phenotypic variability is matched by genetic variability. A traditional approach in addressing 
genetic variation and human difference might be to use Lewontin's (1972) seminal study of diversity among and within populations or one of the many subsequent studies of population structure (e.g., see Rosenberg et al. 2002). While this approach is valuable, few instructors highlight the fact that humans have a high level of phenotypic (i.e., visible) variation that is not mirrored in our genotypic (i.e., not immediately visible) variation. To build support for the biocultural model (i.e., complex phenotypes are the result of genotypic potential, environmental variation, and sociocultural norms and behaviors), it is important to establish that humans compared with other animals are not very genetically variable (e.g., see primate diversity estimates in Kaessmann et al. 2001). Barbujani et al. (2013) also provide an effective overview of human genome diversity via $\mathrm{F}_{\mathrm{ST}}$ estimates, including an example of the misunderstanding and misuse of racial pharmacogenomics.

In natural science courses, an understanding of our low genetic variability builds toward a larger understanding of why mutation and other evolutionary forces that shape our variability are critical to our survival as a species and how behavioral plasticity (of which "culture" is a component) allows us to navigate our lack of genetic diversity. This framework also nicely sets the stage for a discussion of the misconception that disability is a case of "abnormal," and therefore "detrimental," variation (see example 5 below). Further, sex-based and race-based differences begin to rightly appear as a splitting of hairs, given that overall intraspecies variation is so low. Whether a social science or natural science course, an alternative approach to referencing studies that demonstrate high inter-group genetic diversity (and then moving on), would be to provide photographs and statistics for animals with high genotypic and low phenotypic variation as compared with humans of different races or sexes (i.e., low genotypic/ high phenotypic variation). Hubbard (2017b) uses a graphic comparing "identical" penguins versus different human races, though one could also use male/female gorillas (which are highly sexually dimorphic) contrasted with male/female humans to demonstrate differences in sexual dimorphism. To further demonstrate how (relatively high) phenotypic variation is deceiving, the approach to sexual dimorphism in human height (described earlier) can be used. In social science courses, these topics build nicely into discussions of why human differences are not predicated on biology.

\subsection{Misconception 3: Race and Gender Groups Can Be Distinguished Genetically through "Unique” Markers That Do Not Overlap between Groups}

Students operating under genetic, biosomatic, neurogenetic, or other biologically deterministic frameworks are likely to assume there are easily discernible, unique genes associated with particular identities (Dar-Nimrod and Heine 2010). In a more introductory course, an easy way to explore how racial groups are not genetically distinct is to show the American Anthropological Association's "Race: The Power of an Illusion" video (episode 1) or, at least, the vignettes that cover an experiment in the classroom at Cold Springs Harbor. In these vignettes, students of varying races are asked to predict with whom they will share the most genetic similarity. Students of the same so-called race pick one another, only to find post-results that they also shared as much (or in some cases more) variation with students of different races than previously predicted. In more advanced courses, population history and structure analyses (or simulations) can be used to demonstrate how small the genetic variation between populations is, as well as the a priori assumptions inherent in such tests (e.g., see Kalinowski 2011). In these contexts, race is often explicitly addressed or implicitly assumed by students to mean "genetic ancestry" (Yudell et al. 2016); therefore clarification of genetic ancestry as a concept 
related to geographically (not racially) distributed genetic variation is imperative. Further, introducing students to how ancestrally information markers (AIMs) are "discovered" and the limitations of those discoveries (e.g., Shriver et al. 1997; Weiss and Long 2009) is one way to distinguish between ancestry and race. While discussions of inconsistency in calculation of commercial genetic testing ancestry "percentages" is another example of AIMs in popular culture (e.g., see Krimsky and Johnston 2017; Shriver and Kittles 2004).

While related "gender-informative markers" do not exist, it can be helpful to cover the same topic by talking about studies that purport gendered brain differences (i.e., neurological hardwiring) and the myriad reasons adult male/female brains are different (but not for the reasons one might think). For example, in our introductory classes, students are introduced to the fact that gendered behaviors are often attributed to sex-based differences in neurological pathways (i.e., that pattern our ways of thinking). Using studies that demonstrate the plasticity of the brain, as well as the ways in which gendered "learning" shapes our brain's "thinking" (and subsequent neurological pathways), students quickly realize that such differences are acquired through time as opposed to being set at birth, by a particular gene for male/female brain differences. If asked whether, based on this information, there is a sex-specific gene for patterned, gendered thinking students usually conclude that there is not. In this way, physiological differences can be explained as acquired and not genetically pre-determined. Following Donovan et al. (2019b) the approach here is to frame the discussion around whether males are innately "better" at certain cognitive tasks than females. Through an exploration of the acculturation process in shaping cognitive pathways, students are better able to understand how these differences are shaped less by biology and more by culture.

\subsection{Misconception 4: Human Differences Are Predicated on Biology- Bodily (e.g., Visible Phenotypes), Genetic (e.g., Allele Frequencies), Physiological (e.g., Hormonal)-More than Cultural Constructions of Biological Norms or the Impacts of Physical Environmental Changes (e.g., How Time of Day or Temperature Affects Hormones)}

Given the understandably heavy focus of genetics courses on biological variables, it is easy for students to consider utilizing a biologically based framework for understanding how humans vary. For students in both social science and nature science courses, biological explanations are often seen as more objective and "simpler" than cultural explanations. Hubbard (2017a) found that even students who overtly rejected race as biologically based (and embraced sociocultural explanations for racial differences) before beginning her course often still leaned on biological essentialist explanations of racial differences, without realizing it. In other words, even students in a social science course may reject race and gender as biologically based while also (unknowingly) using genetic or biosomatic explanations for those differences. Promisingly, after completing a course where biological and sociocultural explanations of race were covered, Hubbard (2017a) found that students (regardless of initial "beliefs") showed a significant change in understanding of the nature of race/racism as they pertain to biology. Such findings support others' assertions that a biocultural perspective is needed (Hartigan 2006; Morning 2008, 2011, 2014; Mukhopadhyay et al. 2014; Thompson 2006).

In natural and social science courses, exposure to Baker's (1997) explanation of the biocultural approach helps to set the stage that genetics are just one component, among cultural or environmental components, influencing human traits. This approach can be presented as a counter to the notion of Mendelian trait development as the primary way humans 
vary. For example, human sexual desire is often seen as sexually dimorphic due primarily to biological differences (e.g., hormones). Many factors contribute to the misconception that females desire sex less than males because this difference is genetically hardwired at birth. Biologically there are genetic factors such as the DRD4 gene that controls dopamine receptors linked to sexual pleasure, which have been shown to heavily influence experiences of sexual desire (Ben Zion et al. 2006) as well as varying levels of testosterone (e.g., see Shirazi et al. 2018; Stephens-Shields et al. 2019). However, environmentally, time of day and age (e.g., see Long et al. 2015) along with season/temperature (e.g., Demir et al. 2016) have been shown to influence levels of testosterone, progesterone, and estrogen. Finally, sociocultural norms heavily affect one's expression of sexual desire.

Because of students' deeply entrenched, bioessentialist beliefs, it can be challenging for them to consider sociocultural impacts on phenotypes. Try asking your students whether sexual desire will be higher in someone with few dopamine receptors, highly positive associations with sex, and positive environmental conditions for hormones or someone with many dopamine receptors, highly negative associations with sex, and negative environmental conditions for hormones. Some have a definitive answer, though this offers an opportunity to discuss gene expression/penetration effects, variation within single categories (e.g., some with a high sex drive might have more dopamine receptors, while another less), and the power of sociocultural norms (i.e., what is "allowed" to be expressed). A reluctance to accept the validity of the impacts of social and cultural systems is ironic given how much these very norms influence students' own behaviors and decision-making processes. For example, Fisher (2009) found, in American culture in particular, heteronormativity and homophobia have been widely documented as a deterrent in truthful reporting of sexual habits and sexuality. Therefore, using results from studies of sociocultural behaviors such as Fisher (2009) can aid in demonstrating a more holistic picture of the variables affecting sexual desire. Overall, having students consider the influence of all three variables is key to demonstrating that, alone, genetic potential for particular traits does not insure their full expression.

\subsection{Misconception 5: Disabled, Female, and Intersex Are Categories of Abnormal Human Variation (as Opposed to Socioculturally Constructed "Conditions")}

A core comparative principle in studies of human biology is abnormal versus normal biological variation. Theoretically, normality is established from a baseline of varied, representative data, yet numerous studies (especially biomedical) reveal the imbalance in representation of women (e.g., Harris and Douglas 2000) and disabled individuals (e.g., Moore 2012). As such, the tendency is to find research that (implicitly) delineates male and able-bodied individuals as "normal" variation from which female/intersex and disabled bodies deviate. For example, Shansky (2019) provides a solid overview of the problems inherent in psychological research that assume women are more "complex" and "abnormal" with the implication that "[neurologically women are] a disordered, unstable yin to men's rational, orderly yang" (825). Likewise, ableist language around genetic "disorders" and health "risks" shows how many non-lethal disabilities are ubiquitously treated as harmful, rather than forms of "normal human variation." In natural and social science courses, this topic also creates a good starting point at which to bring in discussions on myth construction and what we "think" we know, from earlier sections of this paper.

In the classroom, an alternative to the assumption that "normal" and "abnormal" variation exist in a scientifically objective manner is to discuss such issues in research design. By 
acknowledging the fact that flaws in research design exist, educators allow students to explore the genetics of human difference more "truthfully" than treating science as "neutral." Using the history of science, a discussion of how changing societal and cultural norms influence our perceptions of science can help to contextualize why ideas such as eugenics have changed as well as how personal bias can seep into the process (i.e., the false notion of absolute objectivity). Finally, connecting back to earlier coverage of low human genetic variation, educators can expand to explore the notion of genetic disorders. Where possible, discussing cross-cultural examples of variants producing non-lethal disorders (e.g., albinism) that are celebrated in one country (e.g., some Kenyans find albinism to be special; members of some Hmong communities believe epilepsy marks someone with positive attributes) and discouraged in others (e.g., both albinism and epilepsy are treated as a health "problem" in the US) can further help students grapple with what is "normal" and "abnormal" about particular genetic cases (in a social sense). Such discussions set a solid foundation for further in-depth discussions on the ethics of gene therapy in the context of non-lethal disabilities (i.e., nonlethal "genetic disorders" or "diseases") and whether such treatments improve quality of life or stigmatize difference. These examples provide a way of showing how even talking about the biology of "genetic disorders" shapes sociocultural assumptions about what differences are "normal" and "abnormal" and vice versa.

Additionally, there is a tendency among students to overemphasize cases in which new mutations or genetic drift effects lead to deleterious effects, as opposed to acknowledging times in which such events led to novel and life-saving variants. Such approaches can leave students associating change/mutation with negative outcomes (Condit et al. 2004), instead of as the production of novel, necessary variation into human populations (for a review see e.g., Loewe and Hill 2010). In a natural science course, one might ask students to identify examples of beneficial and harmful mutations that have contributed to human genetic variation. Students will find it easy to identify harmful genetic mutations like Huntington's, because much of the medical literature is focused on identifying the etiology of these lethal "disorders." A good example of a beneficial mutation due to natural selection is the genetic adaptation found in high altitude populations in the Andes, which allow red blood cells to better trap and transport oxygen (e.g., see Beall 2006). These variants are unique to this high altitude population and are therefore "abnormal," yet clearly they provide great benefit to those born in a hypoxic (lowoxygen) environment.

\subsection{Misconception 6: Systemic Oppression Is a Culturally Politicized Topic and Therefore Irrelevant to a Genetics Curriculum}

Traditionally, genetics coursework does not address systemic oppression perhaps, in part, because the root of such behaviors is grounded in socially and culturally specific frameworks. In today's highly charged political climate, when faculty are already being scrutinized for their perceived contributions to any form of political indoctrination (e.g., Fosse et al. 2014), educators may be nervous that these topics will be perceived politically (or are political). Yet, science is not politically or socially neutral despite scientists' best efforts to behave as if it were. And, given the demonstrated relevance of these topics in the examples below, we argue that such topics need to be covered.

In a natural science course, it is important and highly relevant to begin connecting the effects of oppression to changes in the human body. There are, sadly, a number of excellent examples related to the stress of being oppressed. Anthropological research like that of 
Madrigal et al. (2009) provides a solid jumping off point for a discussion of the ramifications of stress, due to racism. The "slavery hypothesis" purports that hypertensive disorders can be tracked to genetically inherited conditions among African-Americans whose ancestors survived the Middle Passage and aspects of diet (Wilson and Grim 1991). Madrigal and colleagues importantly demonstrate how the stress of racism better accounts for higher rates of hypertension among African-American communities than either diet or ancestry. Using cross-cultural samples from black African and Caribbean populations (many of whom have low hypertension rates), this piece embodies the approach advocated in this paper (holistic, cross-cultural, biocultural, culturally relativistic).

Another rich area for exploration is racism-induced stress and epigenetic tagging. In the last 10 years, researchers have finally begun to link epigenetic stress studies to mortality rates among pregnant non-white mothers (e.g., see Goosby and Heidbrink 2013; Kuzawa and Sweet 2009) and disproportionate rates of preterm births and infant mortality in black US populations (e.g., see Smith et al. 2018). Most students will have been introduced to the effects of stereotyping on unequal access to healthcare and preferential treatment by doctors, but few understand how the inherited effects of racism (social) can, albeit indirectly, impact the genome (biological). However, using Serena Williams' or Beyonce Knowles' pre- and postpregnancy complications as examples, students might begin to see that socioeconomics is not always the primary factor. Indeed, as Smith et al. (2018) state, "the [infant mortality rate] is highest for black women with a doctorate or professional degree" (4). These examples are also needed in the social science classroom, given that it has already been noted that students who reject genetically essentialist explanations of human differences may still utilize basic biological explanations to explain human behavioral differences (e.g., see Hubbard 2017a).

These six examples provide a solid framework for talking more intentionally, holistically, bioculturally, relativistically, and cross-culturally about human difference. They can be used in a dedicated section on human difference and genetic variation or dispersed throughout the semester (we do both in our anthropology courses). For those who are uncomfortable jumping into these topics right away, bringing "experts" on genetics and biology (natural science) or sociocultural identity (social science) to lecture in class is a simple way to start. Talking openly and intentionally about why human differences are not due solely to genetics, are socially real and powerful, and yet still relevant to a natural science curriculum can also ease the tension around these topics.

\section{Concluding Remarks}

The purpose of this paper is to challenge educators to explore their own tacit cultural assumptions about science and biology as a means to reframe courses centered on the "genetics" of human difference. Specifically, we advocate for educators to think more broadly about the influence of American sociocultural experiences on construction of knowledge about genetics and human differences, how lived experience shapes individual ideas and variation within group thinking about these concepts, and the ways in which genetics are incorrectly viewed as the most straightforward and accurate way to categorize human differences. As Gay and Kirkland (2003) note, "teachers knowing who they are, understanding the contexts in which they teach, and questioning their knowledge and assumptions are as important as the mastery of techniques for instructional effectiveness" (181); others agree. Cochran-Smith (2005), for example, notes that "teaching for social change" relies on teachers to explore their 
own cultural biases. Philip (2011) demonstrates, through case studies, how faculty who are explicitly aware of structural inequalities and social justice issues can still hold tacit assumptions ("commonsense") and biases that contribute to inequalities.

Using examples from our own classrooms, we attempt to demonstrate some of the common misconceptions about human difference, genetics, and science and how anthropological approaches and concepts can be used to begin to dismantle genetic essentialist thinking about human differences. While not all of these specific interventions have been empirically tested, there is support from other research programs (e.g., Donovan et al. 2019a, b); Hubbard 2017a) that have tested similar approaches. Further, models such as Philip's (2011) "ideology in pieces" (which builds on Wagner's (2006) "transfer in pieces" model) advocate exploring concepts within a wide range of contexts in order to begin seeing how internal inconsistencies or misaligned priorities of learning and practice come into play. Preparing to revise one's curriculum to incorporate new ways of thinking can appear daunting. Remember that such changes take time and will involve some trial and error. If this work was easy, educators would have already come up with a solution. As recommended previously, use your classroom assessments as a tool for determining "successes" and use feedback from students to revise unrealized "failures" in delivery.

Natural science educators cannot continue to teach about the genetics of human difference without understanding and taking time to share the sociocultural context in which discriminatory and oppressive ideologies have emerged. Nor can social science educators ignore how the sociocultural environments that allowed discriminatory and oppressive ideologies to emerge have been shaped by our understanding (or lack thereof about) genetics and biology. As the authors have learned through the "de-siloing" of our classroom environments, teaching about human difference bioculturally has both enhanced our students' understanding of anthropological topics and given a context for how we (often inaccurately) ascribe biological causes for such differences. This practice of knowledge compartmentalization has led to a number of insidious and pervasive myths to continue for far too long, which then undercuts our efforts to collectively train and prepare the next generation. Nowhere is this more evident than pre-med and med school curricula. While a recent move has introduced sociology (and occasionally cultural anthropology) as a component in medical school preparation (and an attempt at holism), there exist significant constraints to developing cohesive messaging. Even questions on the MCAT directly reference and reinforce stereotyping about racialized diseases, creating a contradiction of information in the face of the pragmatic need to prepare students to pass the exam.

Tremendous opportunities exist to improve student understanding of genetic contributions to human difference, yet educators are not taking them. In a study by Bowling et al. (2007), roughly $90 \%$ of colleges offer courses focused on human genetics, yet only $2 \%$ of all college students will complete one of these courses, if they are not a major. Given that only $10 \%$ of the undergraduate population is focused on "life sciences and health" majors, they conclude that non-science majors are missing out on opportunities to engage with genetic content that is directly relevant to their lives. Potentially, the only place where non-majors will learn about the "genetics" is in social science courses, underscoring the need for these educators to take up this work as well. Likewise, though the intended audience of this paper is college faculty, several of the supporting findings from cited studies in this paper are based on K-12 science classrooms. Therefore, these concepts are also appropriate and could be applied in middle school and high school science classrooms. Using these suggested approaches we hope more social science and natural science educators at all levels will begin eliminating barriers to teaching bioculturally about human difference. 


\section{Compliance with Ethical Standards}

Conflicts of Interest The authors declare that they have no conflict of interest.

\section{References}

Agarwal, P. K., \& Bain, P. M. (2019). Powerful teaching. San Francisco: Jossey-Bass.

Ainsworth, C. (2015). Sex redefined. Nature (News), 518(7539), 288-291.

Ancestry. (2018). If you could listen to your DNA, what would it sound like? Retrieved from https://www. ancestry.com/cs/spotify. Accessed 16 Nov 2018.

Antón, S. A., Malhi, R. S., \& Fuentes, A. (2018). Race and diversity in U.S. biological anthropology: a decade of AAPA initiatives. American Journal of Physical Anthropology, 165(S65), 158-180.

Apfelbaum, E. P., Sommers, S. R., \& Norton, M. I. (2008). Seeing race and seeming racist? Evaluating strategic color blindness in social interaction. Journal of Personality and Social Psychology, 95, 918-932.

Baker, P. T. (1997). The Raymond pearl memorial lecture, 1996: the eternal triangle- genes, phenotype, and environment. American Journal of Human Biology, 9, 93-101.

Bang, M., \& Medin, D. (2010). Cultural processes in science education: supporting the navigation of multiple epistemologies. Science Education, 94(6), 1008-1026.

Bang, M., Marin, A., \& Medin, D. (2018). If indigenous peoples stand with the sciences, will scientists stand with us? Daedalus, $147(2), 148-159$.

Barbujani, G., Ghirotto, S., \& Tassi, F. (2013). Nine things to remember about human genome diversity. Tissue Antigens, 82, 155-164.

Bardill, J., Bader, A. C., Garrison, N. A., Bolnick, D. A., Raff, J. A., Walker, A., Malhi, R. S., \& SING. (2018). Advancing the ethics of paleogenomics. Science, 360(6387), 384-385.

Barnes-Karol, G., \& Broner, M. A. (2010). Using images as springboards to teach cultural perspectives in light of the ideals of the MLA report. Foreign Language Annals, 43, 422-445.

Barnhardt, R. (2005). Indigenous knowledge systems and Alaska native ways of knowing. Anthropology and Education Quarterly, 36(1), 8-23.

Bates, B. R. (2005). Public culture and public understanding of genetics: a focus group study. Public Understanding of Science, 14, 47-65.

Beall, C. M. (2006). Andean, Tibetan, and Ethiopian patterns of adaptation to high-altitude hypoxia. Integrative and Comparative Biology, 46(1), 18-24.

Becher, T., \& Trowler, P. R. (2001). Academic tribes and territories: Intellectual enquiry and the culture of disciplines (2nd ed.). Buckingham: Society for Research into Higher Education and Open University Press.

Ben Zion, I. Z., Tessler, R., Cohen, L., Lerer, E., Raz, Y., Bachner-Melman, R., Gritsenks, I., Menamov, L., Zohar, A. H., Belmaker, R. H., Benjamin, J., \& Ebstein, R. P. (2006). Polymorphisms in the dopamine D4 receptor gene (DRD4) contribute to individual differences in human sexual behavior: desire, arousal and sexual function. Molecular Psychiatry, 11(8), 782-786.

Berlin, B. (1992). Ethnobiological classification: principles of categorization of plants and animals in traditional societies. Princeton: Princeton University Press.

Berlin, B., \& Kay, P. (1969). Basic color terms. Berkeley: University of California Press.

Boas, F. (1938). General anthropology. Boston: D.C. Health.

Boas, F. (1940). Race, language, and culture. New York: Macmillan.

Borofsky, R. (1994). Introduction. In R. Borofsky (Ed.), Assessing cultural anthropology (pp. 1-22). New York: McGraw-Hill, Inc..

Bowling, B. V., Huether, C. A., \& Wagner, J. A. (2007). Characterization of human genetics courses for nonbiology majors in U.S. college and universities. CBE Life Science Education, 6(3), 224-232.

Brownell, S. E., Price, J. V., \& Steinman, L. (2013). Science communication to the general public: Why we need to teach undergraduate and graduate students this skill as part of their formal scientific training. Journal of Undergraduate Neuroscience Education, 12(1), E6-E10.

Christensen, K. D., Jayaratne, T., Roberts, J., Kardia, S., \& Petty, E. (2010). Understandings of basic genetics in the United States: results from a national survey of black and white men and women. Public Health Genomics, 13(7-8), 467-476.

Clancy, K. B. H., Nelson, R. G., Rutherford, J. N., \& Hinde, K. (2014). Survey of academic field experiences (SAFE): trainees report harassment and assault. PLoS One, 9(7), e102172. 
Claw, K. G., Lippert, D., Bardill, J., Cordova, A., Fox, K., Yracheta, J. M., Bader, A. C., Bolnick, D. A., Malhi, R. S., TallBear, K., \& Garrison, N. A. (2017). Chaco canyon dig unearths ethical concerns. Human Biology, 89(3), 177-180.

Claw, K. G., Anderson, M. Z., Begay, R. L., Tsosie, K. S., Fox, K., Garrison, N. A., \& SING. (2018). A framework for enhancing ethical genomic research with indigenous communities. Nature Communications, 9(2957), 1-7.

Cochran-Smith, M. (2005). Teacher development and educational reform. In M. Fullan (Ed.), Fundamental change: International handbook of educational change (pp. 27-88). Dordrecht: Springer.

Condit, C. (2001). What is 'public opinion' about genetics? Nature Reviews Genetics, 2, 811-815.

Condit, C.M., Dubriwny, T., Lynch, J. \& Parrott, R. (2004). Lay People's Understanding of and Preference Against the Word "Mutation." American Journal of Medical Genetics, 130A, 245-250.

Conger, K. (2017). Of mice, men, and women: Making research more inclusive. Stanford Medicine https://stanmed.stanford.edu/2017spring/how-sex-and-gender-which-are-not-the-same-thing-influence-ourhealth.html. Accessed 19 Jun 2020.

Dar-Nimrod, I., \& Heine, S. J. (2010). Genetic essentialism: on the deceptive determinism of DNA. Psychological Bulletin, 137(5), 800-818.

Demir, A., Uslu, M., \& Arslan, O. E. (2016). The effect of seasonal variation on sexual behaviors in males and its correlation with hormone levels: a prospective clinical trial. Central European Journal of Urology, 69(3), 285-289.

DiSessa, A. (1993). Toward an epistemology of physics. Cognition and Instruction, 10(2/3), 105-225.

Doat, D. (2014). Evolution and human uniqueness: prehistory, disability, and the unexpected anthropology of Charles Darwin. In D. Bolt (Ed.), Changing social attitudes toward disability: perspectives from historical, cultural, and educational studies (pp. 15-25). New York: Routledge.

Donovan, B. (2014). Playing with fire? The impact of the hidden curriculum in school genetics on essentialist conceptions of race. Journal of Research in Science Teaching, 51(4), 462-496.

Donovan, B. M. (2015). Reclaiming race as a topic of the US biology textbook curriculum. Science Education, 99(6), 1092-1117.

Donovan, B. M., Semmens, R., Keck, P., Brimhall, E., Busch, K. C., Weindling, M., Duncan, A., Stuhlsatz, M., Bracey, Z. B., Bloom, M., Kowalski, S., \& Salazar, B. (2019a). Towards a more humane genetics education: learning about the social and quantitative complexities of human genetic variation research could reduce racial bias in adolescent and adult populations. Science Education, 103(3), 529-560.

Donovan, B. M., Stuhlsatz, M. A. M., Edelson, D. C., \& Buck Bracey, Z. E. (2019b). Gendered genetics: how reading about the genetic basis of sex differences in biology textbooks could affect beliefs associated with science gender disparities. Science Education, 103, 719-749.

Fisher, T. (2009). The impact of socially conveyed norms on the reporting of sexual behavior and attitudes by men and women. Journals of Experimental Social Pyschology, 45(3), 567-572.

Fosse, E., Gross, N., \& Ma, J. (2014). Political bias in higher education: a field experiment. In N. Gross \& S. Simmons (Eds.), Professors and their politics (pp. 109-134). Baltimore: Johns Hopkins University Press.

Friedner, M., Kasnitz, D. \& Wool, Z. (2018). What I wish I knew about anthropology and disability: notes toward a more enabling anthropology [Blog post]. Retrieved from: https:/anthrodendum.org/2018/01/10 /what-i-wish-i-knew-about-anthropology-and-disability-notes-toward-a-more-enabling-anthropology/. Accessed 16 Aug 2019.

Fuentes, A. (2012). Race, monogamy and other lies they told you: busting myths about human nature. Berkeley: University of California Press.

Garrison, N. A. (2013). Genomic justice for native Americans: impact of Havasupai case on genetic research. Science, Technology, \& Human Values, 38(2), 201-223.

Garrison, N. A., Hudson, M., Ballantyne, L. L., Garba, I., Martinez, A., Taualii, M., Arbour, L., Caron, N. R., \& Rainie, S. C. (2019). Genomic research through an indigenous lens: Understanding the expectations. Annual Review of Genomics and Human Genetics, 20, 495-517.

Gay, G., \& Kirkland, K. (2003). Developing cultural critical consciousness and self-reflection in preservice teacher education. Theory Into Practice, 42(3), 181-187.

Gelman, S. A., \& Taylor, M. G. (2000). Gender essentialism in cognitive development. In P. H. Miller (Ed.), Toward a feminist developmental psychology (pp. 169-190). New York: Routledge.

Genz, J. H. (2018). Breaking the shell: voyaging from nuclear refugees to people of the sea in the Marshall Islands. Hilo: University of Hawai'i Press.

Genz, J., Aucan, J., Merrifield, M., Finney, B., Joel, K., \& Kelen, A. (2009). Wave navigation in the Marshall Islands: comparing indigenous and Western scientific knowledge of the ocean. Oceanography, 22(2), 234 245 .

Goldberg, A. D., Allis, C. D., \& Bernstein, E. (2007). Epigenetics: a landscape takes shape. Cell, 128(4), 635638. 
Goodenough, W. (1970). Description and comparison in cultural anthropology. London: Routledge.

Goodman, A. H., Moses, Y. T., \& Jones, J. L. (2012). Race: are we do different? Malden: Wiley-Blackwell.

Goosby, B. J., \& Heidbrink, C. (2013). Transgenerational consequences of racial discrimination for African American health. Sociological Compass, 7(1), 630-643.

Graves, P. R., \& Haystead, T. A. J. (2002). Molecular biologist's guide to proteomics. Microbiology and Molecular Biology Reviews, 66(1), 39-63.

Gravlee, C. C. (2009). How race becomes biology: embodiment of social inequality. American Journal of Physical Anthropology, 39, 47-57.

Greenwood, M. R. C., \& Riordan, D. G. (2001). Civic scientist/civic duty. Science Communication, 23(1), 2840.

Haga, S. B., Barry, W. T., Mills, R., Ginsburg, G. S., Svetkey, L., Sullivan, J., \& Willard, H. F. (2013). Public knowledge of and attitudes toward genetics and genetic testing. Genetic Testing and Biomolecular Markers, $17,327-335$.

Hammer, D. (1996). Misconceptions or p-prims: how may alternative perspectives of cognitive structure influence instructional perceptions and intentions. The Journal of the Learning Sciences, 5(2), 97-127.

Harper, D. (2002). Talking about pictures: a case for photo elicitation. Visual Studies, 17, 13-26.

Harris, M. (1976). History and significance of the emic/etic distinction. Annual Review of Anthropology, 5, 329350 .

Harris, D. J., \& Douglas, P. S. (2000). Enrollment of women in cardiovascular clinical trials funded by the National Heart, Lung, and Blood Institute. New England Journal of Medicine, 343, 475-480.

Hartigan, J. (2006). Saying "socially constructed" is not enough. Anthropology Newsletter, 47, 1-8.

Henrich, J. (2008). A cultural species. In M. Brown (Ed.), Explaining culture scientifically (pp. 184-210). Seattle: University of Washington Press.

Henrich, J., Heine, S. J., \& Norenzayan, A. (2010). Most people are not WEIRD. Nature, 466, 29.

Hodge, F. S. (2012). No meaningful apology for American Indian unethical research abuses. Ethics and Behavior, 22(6), 431-444.

Hrdy, S. B. (1981). The woman that never evolved. Cambridge: Harvard University Press.

Hubbard, A. R. (2017a). Testing common misconceptions about the nature of human racial variation. American Biology Teacher, 79(7), 538-543.

Hubbard, A. R. (2017b). Teaching race (bioculturally) matters: a visual approach for college biology courses. American Biology Teacher, 79(7), 516-524.

Hutchings, R., \& La Salle, M. (2015). Archaeology as disaster capitalism. International Journal of Historical Archaeology, 19(4), 699-720.

Ifekwunigwe, J. O., Wagner, J. K., Yu, J., Harrell, T. M., Bamshad, M. J., \& Royal, C. D. (2017). A qualitative analysis of how anthropologists interpret the race construct. American Anthropology, 119(3), 422-434.

Jackson Jr., J. P., \& Depew, D. J. (2017). Darwinism, democracy, and race: American anthropology and evolutionary biology in the twentieth century. New York: Routledge.

Kaessmann, H., Wiebe, V., Weiss, G., \& Paabo, S. (2001). Great ape DNA sequences reveal a reduced diversity and an expansion in humans. Nature Genetics, 27, 155-156.

Kalinowski, S. T. (2011). The computer program STRUCTURE does not reliably identify the main genetic clusters within species: simulations and implications for human population structure. Heredity, 106, 625632.

Kimel S. Y., Huesmann R., Kunst J. R., \& Halperin E. (2016). Living in a genetic world: how learning about interethnic genetic similarities and differences affects peace and conflict. Personality and Social Psychology Bulletin, 42(5), 688-700.

King, C. (2019). Gods of the upper air. New York: Doubleday.

Knobe, J. (2010). Person as scientist, person as moralist. Behavioral and Brain Sciences, 33, 315-329.

Kolstø, S. D. (2001). Scientific literacy for citizenship: Tools for dealing with the science dimension of controversial socioscientific issues. Science Education, 3, 291-310.

Krimsky, S., \& Johnston, D. C. (2017). Ancestry DNA and privacy: A consumer guide. Council for Responsible Genetics Report. Washington, D.C: International Center for Technology Assessment. https://sites.tufts. edu/sheldonkrimsky/files/2018/05/pub2017AncestryDNAPrivacy.pdf. Accessed 19 Jun 2020.

Kuklinski, J. H., Quirk, P. J., Jerit, J., Schwieder, D., \& Rich, R. F. (2000). Misinformation and the currency of democratic citizenship. Journal of Politics, 62(3), 790-816.

Kuzawa, C. W., \& Sweet, E. (2009). Epigenetics and the embodiment of race: developmental origins of US racial disparities in cardiovascular health. American Journal of Human Biology, 21(1), 2-15.

Lanie, A. D., Jayaratne, T. E., Sheldon, J. P., Kardia, S. L. R., Anderson, E. S., Feldbaum, M., \& Petty, E. M. (2004). Exploring the public understanding of basic genetic concepts. Journal of Genetic Counseling, 4, 305-320. 
Lavenda, R. H., \& Schultz, E. A. (2017[2000]). Core concepts in cultural anthropology. New York: Oxford University press.

Leshner, A. I. (2003). Public engagement with science. Science, 299, 977.

Lewontin, R. (1972). The apportionment of human diversity. In T. Dobzhansky, M. K. Hecht, \& W. C. Steere (Eds.), Evolutionary biology (pp. 381-398). Boston: Springer.

Lieberman, L., Hampton, R. E., Littlefield, A., \& Hallead, G. (1992). Race in biology and anthropology: a study of college texts and professors. Journal of Research in Science Teaching, 29(3), 301-321.

Loewe, L., \& Hill, W. G. (2010). The population genetics of mutations: good, bad and indifferent. Philosophical Transactions of the Royal Society London B (Biological Sciences), 365(1544), 1153-1167.

Long, N., Nguyen, L., \& Stevermer, J. (2015). PURLs: it's time to reconsider early-morning testosterone tests. Journal of Family Practice, 64(7), 418-419.

Lynch, K. E., Morandini, J. S., Dar-Nimrod, I., \& Griffiths, P. E. (2018). Causal reasoning about human behavior genetics: synthesis and future directions. Behavior Genetics, 49(2), 221-234.

Madrigal, L., Blell, M., Ruiz, E., \& Otárola-Durán, F. (2009). The slavery hypothesis: an evaluation of a geneticdeterministic explanation for hypertension prevalence rate inequalities. In C. Panter-Brick \& A. Fuentes (Eds.), Health, risk, and adversity (pp. 236-255). New York: Bergahn Books.

Mahon, B. Z., \& Caramazza, A. (2009). Concepts and categories: a cognitive neuropsychological perspective. Annual Review of Psychology, 60, 27-51.

Malinowski, B. (1922). Argonauts of the Western Pacific. New York: Dutton \& Company.

Marcus, G. E., \& Fischer, M. M. J. (1986). Anthropology as cultural critique: An experimental moment in the human sciences. Chicago: University of Chicago Press.

Marks, J. (2012). The origins of anthropological genetics. Current Anthropology, 53(55), S161-S172.

Marks, J. (2017). Is science racist? (debating race). Malden: Polity Press.

McGee, J. R., \& Warms, R. (Eds.). (1996). Anthropological theory: An introductory history. Mountain View: Mayfield Publishing Company.

Monnig, L. (2007). "Proving Chamorro:" indigenous narratives of race, identity, and decolonization on Guam. University of Illinois at Urbana-Champaign.

Monnig, L. (2008). Adoption is blood: Understanding Chamorro Poksai as Chamorro authenticity within Racialized decolonization politics on Guam. Pacific Studies, 31(3/4), 182-210.

Moore, S. M. (2012). Scientific reasons for including persons with disabilities in clinical and translational diabetes research. Journal of Diabetes Science and Technology, 6(2), 236-241.

Morning, A. (2008). Reconstructing race in science and society: Biology textbooks, 1952-2002. American Journal of Sociology, 114, 106-137.

Morning, A. J. (2011). The nature of race: how scientists think and teach about human difference. Berkeley: University of California Press.

Morning, A. (2014). And you thought we had moved beyond all that: biological race returns to the social sciences. Ethnic and Racial Studies, 37(10), 1676-1685.

Mukhopadhyay, C., Henze, R., \& Moses, Y. T. (2014). How real is race? A sourcebook on race, culture, and biology. Lanham: Altamira Press.

Mullings, L. (2005). Interrogating racism: toward an antiracist anthropology. Annual Review of Anthropology, 34, 667-693.

Norton, M. I., Sommers, S. R., Apfelbaum, E. P., Pura, N., \& Ariely, D. (2006). Color blindness and interracial interaction: playing the political correctness game. Psychological Science, 17, 949-953.

Nyhan, B., \& Reifler, J. (2010). When corrections fail: the persistence of political misperceptions. Political Behavior, 32(2), 303-330.

Nyhan, B., \& Reifler, J. (2015). Does correcting myths about the flu vaccine work? An experimental evaluation of the effects of corrective information. Vaccine, 33, 459-464.

Palazzo, A. F., \& Gregory, T. R. (2014). The case for junk DNA. PLoS Genetics, 10(5), e1004351.

Perry, R. (2003). Five key concepts in anthropological thinking. Upper Saddle River: Prentice Hall.

Petty, E. M., Kardia, S. R., Mahalingham, R., Pfeffer, C. A., Saksewski, S. L., Brandt, M. G., Anderson, E. S., \& Jayaratne, T. E. (2000). Public understanding of genes and genetics: Implications for the utilization of genetic services and technology. American Journal of Human Genetics, 4, 253.

Philip, T. (2011). An "ideology in pieces" approach to studying change in teachers' sense making about race, racism, and racial justice. Cognition and Instruction, 29(3), 297-329.

Plaut, V. C., Thomas, K. C., Hurd, K., \& Romano, C. A. (2018). Do color blindness and multiculturalism remedy or foster discrimination and racism? Current Directions in Psychological Science, 27(3), 200-206.

Potts, R. (2013). Hominin evolution in settings of strong environmental variability. Quaternary Science Reviews, $73,1-13$.

Rosenberg, N. A., Pritchard, J. K., Weber, J. L., Cann, H. M., Kidd, K. K., Zhivatovsky, L. A., \& Feldman, M. W. (2002). Genetic structure of human populations. Science, 298, 2381-2385. 
Schiebinger, L., \& Stefanick, M. L. (2016). Gender matters in biological research and medical practice. Journal of the American College of Cardiology, 67(2), 136-138.

Schommer-Aikins, M., \& Hunter, R. (2002). Epistemological beliefs and thinking about everyday controversial issues. Journal of Psychology, 136(1), 5-20.

Shansky, R. M. (2019). Are hormones a "female problem" for animal research? Science, 364(6443), 825-826.

Shirazi, T. N., Bossi, J. A., Puts, D. A., \& Chivers, M. L. (2018). Menstrual cycle phase predicts women's hormonal responses to sexual stimuli. Hormones and Behavior, 103, 45-53.

Shriver, M. D., \& Kittles, R. A. (2004). Genetic ancestry and the search for personalized genetic histories. Nature Reviews Genetics, 5(8), 611-618.

Shriver, M. D., Smith, M. W., Jin, L., Marcini, A., Akey, J. M., Deka, R., \& Ferrell, R. E. (1997). Ethnicaffiliation estimation by use of population-specific DNA markers. American Journal of Human Genetics, 60(4), 957-964.

Sillitoe, P. (2007). Local science vs. global science: approaches to indigenous knowledge in international development. New York: Berghahn books.

Smerecnik, C., Mesters, I., de Vries, N., \& de Vries, H. (2008). Educating the general public about multifactorial genetic disease: applying a theory-based framework to understand current public knowledge. Genetics in Medicine, 10, 251-258.

Smith, L. T. (2012). Decolonizing methodologies: Research and indigenous peoples (Second ed.). London: Zed Books Ltd..

Smith, E. E., \& Medin, D. L. (1981). Categories and concepts. Cambridge: Harvard University Press.

Smith, I.Z., Bentley-Edwards, K.L., El-Amin, S. \& Darity Jr, W. (2018). Fighting at birth: Eradicating the blackwhite infant mortality gap. Duke University Samuel DuBois Cook Center on Social Equity and Insight Center for Community Economic Development. March report, 1-16. https://socialequity.duke.edu/wpcontent/uploads/2019/12/Eradicating-Black-Infant-Mortality-March-2018.pdf. Accessed 21 Nov 2018.

Snyder, V. L., \& Broadway, F. S. (2004). Queering high school biology textbooks. Journal of Research in Science Teaching, 41(6), 617-636.

Stephens-Shields, A. J., Wang, C., Preston, P., Snyder, P. J., \& Swerdloff, R. S. (2019). Clinically meaningful change in sexual desire in the psychosexual daily questionnaire in older men from the TTrials. The Journal of Sexual Medicine, 16(7), 951-953.

Stilgoe, J., Lock, S. J., \& Wildson, J. (2014). Why should we promote public engagement with science? Public Understanding of Science, 23(1), 4-15.

Sussman, R. W. (2014). The myth of race: the troubling persistence of an unscientific idea. Cambridge: Harvard University Press.

Tapia, I. S., Krajcik, J., \& Reiser, B. (2018). "We do not know what is the real story anymore": Curricular contextualization principles that support indigenous students in understanding natural selection. Journal of Research in Science Teaching, 55(3), 348-376.

Thompson, E. C. (2006). The problem of "race as a social construct". Anthropology Newsletter, 47, 6-7.

Wagner, J. (2006). Transfer in pieces. Cognition and Instruction, 24(1), 1-71.

Wagner, J. K., Yu, J., Ifekwunigwe, J. O., Harrell, T. M., Bamshad, M. J., \& Royal, C. D. (2016). Anthropologists' views on race, ancestry, and genetics. American Journal of Physical Anthropology, 162(2), 318-327.

Weiss, K. M., \& Long, J. C. (2009). Non-Darwinian estimation: My ancestors, my Gene's ancestors. Genome Research, 19, 703-710.

Welsch, R. L., \& Endicott, K. M. (Eds.). (2006). Taking sides: Clashing views in cultural anthropology. Dubuque, IA: McGraw-Hill.

Wiley, A. S., \& Allen, J. (2017). Medical anthropology: A biocultural approach (4th ed.). New York: Oxford Univesity Press.

Williams, M. J., \& Eberhardt, J. L. (2008). Biological conceptions of race and the motivation to cross racial boundaries. Journal of Personality and Social Psychology, 94(6), 1033-1047.

Willinsky, J. (2020). The confounding of race in high school biology textbooks, 2014-2019. Science and Education unassigned. https://link.springer.com/article/10.1007\%2Fs11191-020-00104-y. Accessed 2 Sep 2019.

Wilson, T. W., \& Grim, C. E. (1991). Biohistory of slavery and blood pressure differences in blacks today. Hypertension, 17(Suppl), I122-I128.

Wolf, E. R. (1964). Anthropology. New York: W.W. Norton.

Yudell, M., Roberts, D., DeSalle, R., \& Tishkoff, S. (2016). Taking race out of human genetics. Science, 351, $564-565$.

Publisher's Note Springer Nature remains neutral with regard to jurisdictional claims in published maps and institutional affiliations. 